\title{
CLASSIFICAÇÃO E CUSTOS DE ESTRADAS EM FLORESTAS PLANTADAS NA REGIÃO SUDESTE DO BRASIL ${ }^{1}$
}

\author{
Eduardo da Silva Lopes ${ }^{2}$, Carlos Cardoso Machado e Amaury Paulo de Souza ${ }^{3}$
}

\begin{abstract}
RESUMO - A classificação de estradas florestais é essencial, pois permite o diálogo sem problemas de terminologia, dando subsídios ao planejamento que visa a implantação, conservação e avaliação das estradas existentes. Os objetivos deste trabalho foram elaborar uma classificação de estradas florestais, estimar seus respectivos custos de construção e aplicar esta classificação em uma empresa florestal brasileira. Através da combinação de índices de qualidade foram obtidos, de forma hierarquizada, 20 diferentes classes de estradas com a respectiva velocidade operacional do veículo de transporte e 120 diferentes tipos de estradas com seus respectivos custos de construção. $\mathrm{Na}$ região onde se realizou esta pesquisa, observaram-se três categorias de estradas: principais, secundárias e terciárias, cuja estimativa de custos de construção foi $\mathrm{R} \$ 9.050,00, \mathrm{R} \$ 4.050,00$ e $\mathrm{R} \$ 2.937,00 / \mathrm{km}$, respectivamente.
\end{abstract}

Palavras-chave: Estradas florestais, classificação, custos e construção.

\section{CLASSIFICATION AND COSTS OF FOREST ROADS}

\begin{abstract}
The classification of forest roads is essential because it allows communication without terminology problems, providing subsidies to the planning, implementation, conservation and evaluation of the existing roads. The objective of this work was to elaborate a classification of forest roads and their respective construction costs and apply this classification to a Brazilian forest company. Through the combination of quality indexes, 20 different classes of roads were obtained with their respective transport vehicle operational speed and 120 different types of roads were obtained with their respective construction costs. In the area where this work was conducted, three categories of road were observed: main, secondary and tertiary, with construction cost estimate of R\$9050.00, $R \$ 4050.00$ and $R \$ 2937.00 / \mathrm{km}$, respectively.
\end{abstract}

Key words: $\quad$ Forest roads, classification, costs, construction.

\section{INTRODUÇÃO}

As estradas florestais são as mais importantes vias de acesso às florestas, servindo para viabilizar o tráfego de mão-de-obra e os meios de produção, necessários para implantação, proteção, colheita e transporte dos produtos florestais (Machado, 1989). Elas têm como principais características o baixo volume de tráfego, às vezes temporário, e o tráfego pesado e extrapesado, ocorrendo normalmente em um único sentido, por meio de veículos com capacidade de carga entre 30 e 40 toneladas e de veículos com carga acima de 40 toneladas, respectivamente.
Na década de 80 , estimava-se a extensão da malha rodoviária florestal brasileira em 600 mil quilômetros (Machado \& Malinovski, 1986), podendo este número ter aumentado consideravelmente com o decorrer das novas ampliações das empresas florestais. Também, aumentaram nos últimos anos as exigências em termos de solicitações dessas estradas, devido ao aumento do volume de tráfego de veículos de alta tonelagem; ao aumento das distâncias de transporte em rodovias de baixa qualidade; à necessidade de trafegabilidade durante todo o ano; e à necessidade de estradas com maior vida útil. Por isto, o setor de estradas tem adquirido grande

1 Recebido para publicação em 28.3.2001.

Aceito para publicação em 20.6.2002.

2 Prof. da Universidade Estadual do Centro-Oeste - UNICENTRO, BR 153, Km 7, Riozinho, Caixa Postal, 21, 84500-000 Irati-PR. ${ }^{3}$ Prof. do Departamento de Engenharia Florestal da Universidade Federal de Viçosa, 36571-000 Viçosa-MG. 
importância dentro do empreendimento florestal, uma vez que os custos do binômio estrada-transporte incidem, significativamente, sobre o valor final da madeira.

Comastri \& Carvalho (1981) relataram que as estradas podem ser classificadas de acordo com a sua importância, o modo de construção e o material empregado. Segundo Machado (1989), existem no Brasil muitas divergências quanto à qualidade da rede rodoviária florestal entre as regiões e as empresas do setor, devendo ser ressaltado que poucas possuem um sistema de classificação próprio com seus respectivos padrões, em virtude da inexistência de uma classificação de estradas florestais em nível nacional.

Outro aspecto importante diz respeito ao padrão das estradas, uma vez que ele influencia os custos de construção, de manutenção e de transporte, especialmente através de suas geometrias horizontal e vertical, da qualidade da superfície da pista de rolamento e da largura. $\mathrm{O}$ padrão também influencia o desempenho energético dos veículos, a durabilidade dos pneus e a eficiência operacional dos veículos (Machado, 1989). Portanto, torna-se importante estabelecer um sistema de classificação de forma a permitir o diálogo sem problemas de terminologia e dar subsídios ao planejamento, visando a implantação, conservação e avaliação das estradas existentes.

Este trabalho teve como objetivos elaborar uma classificação com diferentes classes e tipos de estradas em florestas plantadas para a Região Sudeste do Brasil, estimar os seus respectivos custos de construção e aplicar esta classificação em uma empresa florestal.

\section{MATERIAL E MÉTODOS}

Este trabalho foi realizado com dados obtidos no mercado e em literaturas especializadas e os resultados foram posteriormente aplicados na Duratex S.A., empresa que produz madeira serrada para Pallets, MDF e Flooring, situada no município de Agudos, Estado de São Paulo. O projeto estudado está localizado entre as coordenadas $22^{\circ} 15^{\prime}$ e $22^{\circ} 30^{\prime} \mathrm{S}$ e $48^{\circ} 45^{\prime}$ e $49^{\circ} 00^{\prime}$, em uma área total de 13.593 ha, dos quais em torno de 11.800 ha de efetivo plantio (Figura 1).

\subsection{Critérios de Classificação de Estradas Florestais}

Os critérios adotados para classificação das estradas florestais foram a combinação de alguns parâmetros de qualidade que influenciam o desempenho dos veículos de transporte e os custos de construção, as quais foram subdivididas quanto à classe e quanto ao tipo de estrada.

Foram combinados os seguintes parâmetros de qualidade para identificação das estrada quanto à classe: geometria horizontal, largura e tipo de revestimento da superfície da pista de rolamento. As classes de estradas obtidas foram hierarquizadas da melhor para a pior, utilizando como referência o desempenho do veículo de transporte. Para tal, utilizou-se o sistema TRANSROAD, desenvolvido por Machado (1991), para simulação da velocidade média de um veículo 6 X4 com $200 \mathrm{cv}$ de potência e carregado com 20 toneladas de peso bruto total (PBT).

\section{a) Geometria Horizontal}

O índice de geometria horizontal $(\mathrm{GH})$ é um fator calculado pela razão do raio médio de curvas de concordância horizontal de um segmento variável de estrada e o número de curvas por quilômetro, através da seguinte expressão:

$$
\mathrm{GH}=\frac{\mathrm{R}}{\mathrm{NC}}
$$

em que $\mathrm{R}=$ raio médio da(s) curva(s) de um segmento variável de estrada $(\mathrm{m})$; e $\mathrm{NC}=$ número de curvas por quilômetro.

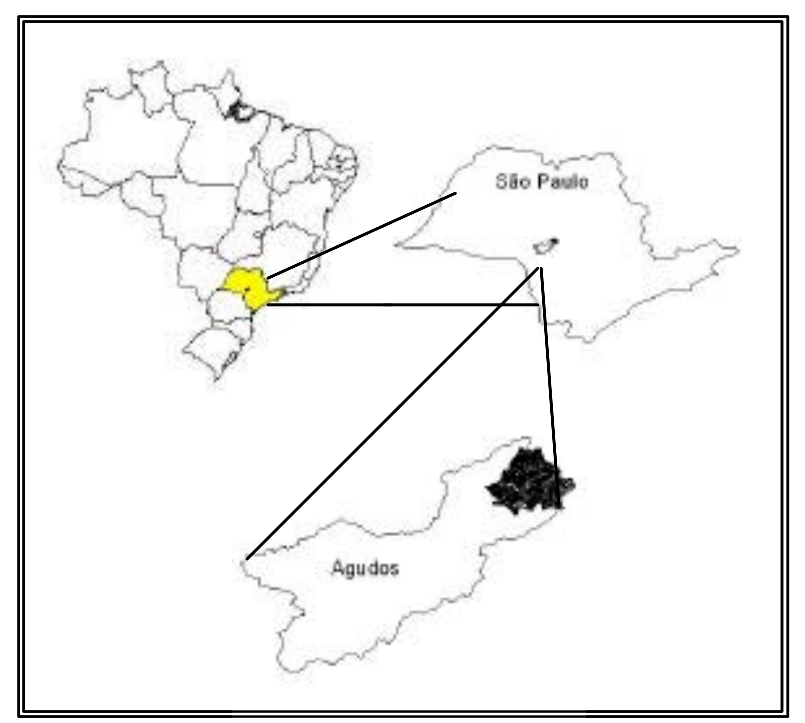

Figura 1 - Localização da região de estudo. Figure 1 - Study area location. 
Para classificar as estradas quanto ao índice de GH, utilizou-se a classificação subjetiva de Sessions \& Sessions (1992), transformada para o sistema métrico (Quadro 1).

Quadro 1 - Classes de geometria horizontal Table 1 - Subjective alignment classification

\begin{tabular}{|c|c|}
\hline Classificação Subjetiva & Valor \\
\hline Excelente & $\geq 48$ \\
Boa & $25-47$ \\
Média & $10-24$ \\
Ruim & $<10$ \\
\hline
\end{tabular}

\section{b) Largura}

- Estrada com pista simples: Possui pista de rolamento com faixa única e largura inferior a $5 \mathrm{~m}$, o que permite o tráfego de veículos em único sentido, mas com faixa de ultrapassagem distribuída ao longo da rodovia.

- Pista dupla: Possui pista de rolamento com duas faixas e largura superior a $7 \mathrm{~m}$, o que permite que dois veículos possam cruzar ou ultrapassar, sem haver redução drástica da velocidade de operação.

\section{c) Superfície da Pista de Rolamento}

- Estrada pavimentada: É aquela revestida com concreto betuminoso ou concreto com cimento, o que permite $o$ tráfego de veículos durante todo o ano.

- Estrada com revestimento primário: É aquela revestida com material granular (saibros, cascalhos etc.), o que permite o tráfego de veículos durante todo o ano.

- Estrada sem revestimento: É aquela que não apresenta qualquer tipo de revestimento, portanto, geralmente, não ocorre o tráfego de veículos durante a época chuvosa.

Os critérios adotados para classificação, visando a obtenção dos custos de construção, foram a combinação dos seguintes parâmetros de qualidade: geometria horizontal, largura, tipo de superfície da pista de rolamento, relevo e tipo de solo do subleito da estrada. Os três primeiros foram os mesmos descritos anteriormente, enquanto para o greide e o tipo de solo de subleito procedeu-se da seguinte forma:

\section{a) Greide}

Os critérios de classificação quanto ao relevo foram convencionados em três tipos:
- Estrada com greide inferior a 5\% (relevo plano).

- Estrada com greide entre 6 e $8 \%$ (relevo ondulado).

- Estrada com greide entre 9 e 15\% (relevo montanhoso).

\section{b) Solos de Subleito}

Adotou-se a classificação "Highway Research Board" (HRB), dividindo-se os solos em dois grandes grupos (Senço, 1997):

- Solos granulares: Constituído por material granular contendo $35 \%$ ou menos de material com diâmetro menor que $0,074 \mathrm{~mm}$.

- Solos Finos: Constituído por material siltoso e argiloso contendo mais do que $35 \%$ de material com diâmetro menor que $0,074 \mathrm{~mm}$.

\subsection{Custo de Construção de Estrada Florestal}

O custo de construção foi estimado para cada tipo de estrada, por meio do somatório dos custos das atividades envolvidas na construção: levantamento topográfico; limpeza e terraplanagem; drenagem; e pavimentação (revestimento primário ou asfáltico). As informações foram obtidas nas empresas prestadoras de serviços de construção de rodovias vicinais no Estado de Minas Gerais e no Departamento de Estradas de Rodagem de Minas Gerais (DER-MG).

\section{a) Levantamento Topográfico}

Os custos com levantamento topográfico referemse aos serviços realizados por uma equipe de um topógrafo e três ajudantes.

\section{b) Limpeza e Terraplanagem}

Os custos de limpeza e terraplanagem referem-se às atividades de corte de árvores, destoca, remoção de resíduos, remoção da matéria orgânica, execução de corte e aterro e compactação.

\section{c) Drenagem}

Os custos de drenagem referem-se à construção de bueiros e sarjetas e à colocação de manilhas.

\section{d) Pavimentação}

Estes custos foram subdivididos em: pavimentação com revestimento primário (cascalho) obtido em jazida a uma distância média de $5 \mathrm{~km}$ e com $10 \mathrm{~cm}$ de espessura; e pavimentação com revestimento asfáltico, com espessura de $3 \mathrm{~cm}$ e base de $20 \mathrm{~cm}$. Os custos de pavimentação

R. Árvore, Viçosa-MG, v.26, n.3, p.329-338, 2002 
asfáltica foram estimados a partir de informações do DER-MG, considerando as seguintes atividades: regularização do subleito, escavação de material de jazida, revestimento primário, imprimação, pintura de ligação e concreto betuminoso usinado a quente, conforme mostrado no Quadro 2.

Quadro 2 - Custos de pavimentação asfáltica Table 2 -Asphalt pavement costs

\begin{tabular}{|l|c|c|}
\hline \multicolumn{1}{|c|}{ Atividade } & Unidade & $\begin{array}{c}\text { Preço Unitário } \\
\text { (R\$) }\end{array}$ \\
\hline Regularização do subleito & $\mathrm{m}^{2}$ & 0,59 \\
Escavação de material de jazida & $\mathrm{m}^{3}$ & 2,82 \\
Revestimento primário & $\mathrm{m}^{3}$ & 4,00 \\
Imprimação & $\mathrm{m}^{2}$ & 0,09 \\
Pintura de ligação & $\mathrm{m}^{2}$ & 0,26 \\
Concreto betuminoso usinado a & $\mathrm{m}^{3}$ & 114,44 \\
quente (CBUQ) & & \\
\hline
\end{tabular}

Fonte: DER-MG (1999).

A escavação de material de jazida referiu-se à obtenção e ao transporte do material até o local de utilização, enquanto o revestimento primário referiu-se à realização do espalhamento e à compactação desse material.

\subsection{Classificação das Estradas: Um Estudo de Caso}

Foram consideradas todas as estradas da área de realização da pesquisa, sendo estas previamente agrupadas em três categorias: estradas principais, secundárias e terciárias. O procedimento para obtenção dos valores de $\mathrm{GH}$, largura, tipo de superfície da pista de rolamento, greide e tipo de solo de subleito dentro de cada categoria foi:

\section{a) Geometria Horizontal}

Os índices de GH foram determinados pelo raio médio das curvas e o número de curvas por quilômetro, através de levantamento de campo. Para tal, foram utilizados de teodolito, mira e trena.

\section{b) Largura}

A largura foi obtida através de informações do banco de dados da empresa e por meio de levantamento de campo, para aferição.

R. Árvore, Viçosa-MG, v. 26, n.3, p.329-338, 2002

\section{c) Superfície de Rolamento}

O tipo de revestimento da superfície de rolamento foi determinado através de mapa fornecido pela empresa e por meio de reconhecimento de campo para aferição.

\section{d) Greide}

O greide das estradas foi determinado mediante informações obtidas na empresa.

\section{e) Solo de Subleito}

A determinação do tipo de solo de subleito foi feita através de ensaios geotécnicos, obedecendo às recomendações da NBR 6457/86. Para tal, efetuou-se a coleta de amostras, utilizando a carta de solos da empresa, que estava estratificava em seis perfis. Procedeu-se então à coleta de uma amostra dentro de cada categoria de estrada situada em cada perfil. Os ensaios geotécnicos foram realizados conforme descrito por Fernandes (2000):

- Análise granulométrica conjunta: Foi realizada na porção do solo que passou na peneira de número 10 , obedecendo à norma NBR 7.181/82 - Solos.

- Massa específica do solo: Foi realizada em todas as amostras de solos, seguindo a norma NBR 6.508/80 Determinação da massa específica dos grãos de solo.

- Limites de Atterberg: As determinações dos limites de liquidez (LL) e de plasticidade (LP) seguiram às normas NBR 6.459/84 e 7.180/94.

- CBR: A capacidade de suporte dos solos foi determinada através do índice de CBR, conforme procedimento recomendado pela norma NBR 9895/87.

\section{RESULTADOS E DISCUSSÃO}

\subsection{Classificação das Estradas Florestais}

Os resultados da classificação de estradas possíveis de ocorrer no setor florestal foram subdivididos quanto ao tipo e à classe de estrada.

\subsubsection{Quanto à Classe}

Mediante a combinação dos parâmetros de qualidade, foram obtidas, de forma hierarquizada, com base no desempenho do veículo de transporte (velocidade operacional), 20 diferentes classes de estradas florestais, as quais foram compiladas no Quadro 3, da melhor combinação para a pior. 
Quadro 3 - Classes de estradas florestais

Table 3 - Forest road classes

\begin{tabular}{|c|c|c|c|}
\hline \multirow{2}{*}{$\begin{array}{c}\text { Classe } \\
\left(\mathrm{n}^{\circ}\right) \\
\end{array}$} & \multicolumn{2}{|c|}{ Parâmetro de Qualidade } & \multirow{2}{*}{$\begin{array}{l}\text { Velocidade } \\
(\mathrm{km} / \text { hora })\end{array}$} \\
\hline & $\mathrm{GH}$ & Largura/Superfície da Pista Rolamento & \\
\hline 1 & Excelente & Pista dupla pavimentação asfáltica & 80,0 \\
\hline 2 & Boa & Pista dupla pavimentação asfáltica & 67,0 \\
\hline 3 & Média & Pista dupla pavimentação asfáltica & 62,3 \\
\hline 4 & Ruim & Pista dupla pavimentação asfáltica & 58,4 \\
\hline 5 & Excelente & Pista dupla revestimento primário & 41,0 \\
\hline 6 & Excelente & Pista simples revestimento primário & 38,8 \\
\hline 7 & Boa & Pista dupla revestimento primário & 38,6 \\
\hline 8 & Média & Pista dupla revestimento primário & 37,0 \\
\hline 9 & Boa & Pista simples revestimento primário & 36,5 \\
\hline 10 & Ruim & Pista dupla revestimento primário & 35,6 \\
\hline 11 & Média & Pista simples revestimento primário & 34,3 \\
\hline 12 & Excelente & Pista dupla sem revestimento & 33,0 \\
\hline 13 & Ruim & Pista simples revestimento primário & 30,8 \\
\hline 14 & Boa & Pista dupla sem revestimento & 30,3 \\
\hline 15 & Excelente & Pista simples sem revestimento & 29,0 \\
\hline 16 & Média & Pista dupla sem revestimento & 28,7 \\
\hline 17 & Ruim & Pista dupla sem revestimento & 27,4 \\
\hline 18 & Boa & Pista simples sem revestimento & 26,6 \\
\hline 19 & Média & Pista simples sem revestimento & 24,3 \\
\hline 20 & Ruim & Pista simples sem revestimento & 20,9 \\
\hline
\end{tabular}

Nessa classificação não foram consideradas as estradas florestais que apresentam pista simples revestida com pavimentação asfáltica, por serem elas de difícil ocorrência no setor florestal.

\subsubsection{Quanto ao Tipo}

Através da combinação dos parâmetros de qualidade que influenciam a construção, obteve-se uma classificação com 120 tipos diferentes de estradas de possível ocorrência no setor florestal, conforme apresentado no Quadro 4. Como pode ser observado, as estradas com pista simples e pavimentação asfáltica não foram contempladas, em função de serem de difícil ocorrência.

\subsection{Custos de Construção de Estradas Florestais}

Com base nas atividades que fazem parte da construção: levantamento topográfico, limpeza e terraplanagem da faixa estradal, drenagem e pavimentação, foram obtidos os valores de custos de construção para cada tipo de estrada obtida na classificação do Quadro 4. A variação nos valores de custos de construção ocorreu, principalmente, em função do greide, da largura e do tipo de revestimento da pista de rolamento.

Nas estradas com pista dupla e pavimentação asfáltica, este tipo de revestimento representou 90,8, 89,3 e $87,8 \%$ dos custos totais de construção, quando em terrenos planos, ondulados e montanhosos, respectivamente. Nas estradas com pista dupla e revestimento primário, este representou 55,3, 43,0 e 35,3\% dos custos totais de construção, quando em terrenos planos, ondulados e montanhosos, respectivamente. Já nas estradas com pista simples, o revestimento primário representou 51,6, 40,1 e $32,7 \%$ dos custos totais, quando em terrenos planos, ondulados e montanhosos, respectivamente. Pode-se verificar que este decréscimo se deve ao aumento dos outros custos de infra-estrutura, principalmente a drenagem. 
Quadro 4 - Tipos de estradas florestais e respectivos custos de construção

Table 4-Types of forest roads type and their respective construction costs

\begin{tabular}{|c|c|c|c|c|c|c|c|c|c|c|c|}
\hline \multicolumn{5}{|c|}{ Parâmetro de Qualidade } & \multicolumn{6}{|c|}{ Atividade da Construção } & \multirow{3}{*}{$\begin{array}{c}\text { Custo } \\
\text { Total } \\
(\mathrm{R} \$ / \mathrm{km})\end{array}$} \\
\hline \multirow[b]{2}{*}{ Tipo } & \multirow[b]{2}{*}{ GH } & \multirow{2}{*}{$\begin{array}{c}\text { Solo } \\
\text { Subleito }\end{array}$} & \multirow[b]{2}{*}{ Greide } & \multirow[b]{2}{*}{ Largura/Tipo Pavimento } & \multirow{2}{*}{\begin{tabular}{|c|} 
Lev. \\
topog. \\
$(\mathrm{R} \$ / \mathrm{km})$
\end{tabular}} & \multirow{2}{*}{\begin{tabular}{|c|} 
Limp+ \\
terrap. \\
$(\mathrm{R} \$ / \mathrm{km})$
\end{tabular}} & \multirow{2}{*}{$\begin{array}{c}\text { Drenagem } \\
(\mathrm{R} \$ / \mathrm{km})\end{array}$} & \multicolumn{3}{|c|}{ Pavimentação (R $\$ / \mathrm{km})$} & \\
\hline & & & & & & & & $\begin{array}{c}\text { Rev. } \\
\text { Primário }\end{array}$ & $\begin{array}{c}\text { Rev. } \\
\text { Asfáltico }\end{array}$ & $\begin{array}{l}\text { Sem } \\
\text { Rev. }\end{array}$ & \\
\hline 1 & Excelente & Finos & Plano & sta dupla pavimentada & 720,00 & $1.530,00$ & $1.800,00$ & & $40.160,40$ & & $44.210,40$ \\
\hline 2 & Excelente & Finos & lano & ista dupla revestimento primário & 720,00 & $1.530,00$ & $1.800,00$ & $5.000,00$ & - & - & $9.050,00$ \\
\hline 3 & Excelente & Finos & Plano & ista dupla sem revestimento & 720,00 & $1.530,00$ & $1.800,00$ & - & - & - & $4.050,00$ \\
\hline 4 & Excelente & Finos & Plano & Pista simples revestimento primário & 720,00 & 957,00 & $1.260,00$ & $3.125,00$ & - & - & $6.062,00$ \\
\hline 5 & Excelente & Finos & Plano & Pista simples sem revestimento & 720,00 & 957,00 & $1.260,00$ & - & - & - - & $2.937,00$ \\
\hline 6 & Boa & Finos & Plano & ista dupla pavimentada & 720,00 & $1.530,00$ & $1.800,00$ & & $40.160,40$ & & $44.210,40$ \\
\hline 7 & Boa & Finos & Plano & Pista dupla revestimento primário & 720,00 & $1.530,00$ & $1.800,00$ & $5.000,00$ & - & - & $9.050,00$ \\
\hline 8 & Boa & Finos & Plano & Pista dupla sem revestimento & 720,00 & $1.530,00$ & $1.800,00$ & - & - & - & $4.050,00$ \\
\hline 9 & Boa & Finos & Plano & Pista simples revestimento primário & 720,00 & 957,00 & $1.260,00$ & $3.125,00$ & - & 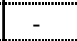 & $6.062,00$ \\
\hline 10 & Boa & Finos & Plano & sta sin & 720,00 & 957,00 & $1.260,00$ & - & $\begin{array}{l}- \\
-\end{array}$ & - & $2.937,00$ \\
\hline 11 & Média & Finos & Plano & Pista dupla pavimentada & 720,00 & $1.530,00$ & $1.800,00$ & & $40.160,40$ & & $44.210,40$ \\
\hline 12 & Média & Finos & Plano & Pista dupla revestimento primário & 720,00 & $1.530,00$ & $1.800,00$ & $5.000,00$ & - & - & $9.050,00$ \\
\hline 13 & Média & Finos & Plano & (a) & 720,00 & $1.530,00$ & 0,00 & - & - & - & $4.050,00$ \\
\hline 14 & Média & Finos & Plano & 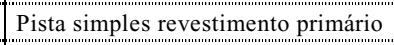 & 720,00 & 957,00 & $1.260,00$ & 3.125 & - & - & $\begin{array}{l}6.062,00 \\
.600\end{array}$ \\
\hline 15 & Média & Finos & Plano & sem revestimento & 720,00 & 957,00 & $1.260,00$ & - & - & - & $2.937,00$ \\
\hline 16 & Ruim & Finos & Plano & 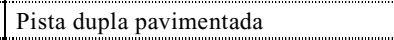 & 720,00 & $1.530,00$ & $1.800,00$ & & $40.160,40$ & & $44.210,40$ \\
\hline 17 & Ruim & Finos & $\mathrm{Pla}$ & ( & 720,00 & $1.530,00$ & 0,00 & $5.000,00$ & - & - & $9.050,00$ \\
\hline 18 & Ruim & Finos & Plano & Pista dupla sem revestimento & 720,00 & $1.530,00$ & $1.800,00$ & "- & - & - & $4.050,00$ \\
\hline 19 & Ruim & Finos & Plano & Pista simples revestimento primário & 720,00 & 957,00 & $1.260,00$ & $3.125,00$ & - & - & $6.062,00$ \\
\hline 20 & Ruim & Finos & Plano & Pista simples sem revestimento & 720,00 & 957,00 & $1.260,00$ & - & - & 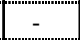 & $2.937,00$ \\
\hline 21 & Excelente & Granulares & Plano & Pista dupla pa & 720,00 & $1.530,00$ & $1.800,00$ & & $40.160,40$ & & $44.210,40$ \\
\hline 22 & Excelente & Granulares & Plano & Pista dupla revestimento primário & 720,00 & $1.530,00$ & $1.800,00$ & $5.000,00$ & - & - & $9.050,00$ \\
\hline 23 & Excelente & Granulares & Plano & Pista dupla sem revestimento & 720,00 & $1.530,00$ & $1.800,00$ & - n l- & - & - & $4.050,00$ \\
\hline 24 & Excelente & Granulares & Plano & Pista simples revestimento primário & 720,00 & 957,00 & $1.260,00$ & $3.125,00$ & - & - & $6.062,00$ \\
\hline 25 & Excelente & Granulares & Plano & sta s & 720,00 & 957,00 & $1.260,00$ & - & - & - & $2.937,00$ \\
\hline 26 & Boa & Granulares & Plano & Pista dupla pavimentada & 720,00 & $1.530,00$ & $1.800,00$ & & $40.160,40$ & & $44.210,40$ \\
\hline 27 & Boa & Granulares & Plano & Pista dupla revestimento $\mathrm{p}$ & 720,00 & $1.530,00$ & $1.800,00$ & $5.000,00$ & - & - & $9.050,00$ \\
\hline 28 & Boa & Granulares & Plano & nto & 720,00 & $1.530,00$ & & - & - & - & $4.050,00$ \\
\hline 29 & Boa & Granulares & Plano & Pista simples reve & 720,00 & 957,00 & $1.260,00$ & $3.125,00$ & - & - & $6.062,00$ \\
\hline 30 & Boa & Granulares & Plano & Pista simples sem revestimento & 720,00 & 957,00 & $1.260,00$ & - & - & - & $2.937,00$ \\
\hline 31 & Média & Granulares & Plano & Pista dupla pavimentada & 720,00 & $1.530,00$ & $1.800,00$ & & $40.160,40$ & & $44.210,40$ \\
\hline 32 & Média & Granulares & Plano & Г Р & 720,00 & $1.530,00$ & $1.800,00$ & $5.000,00$ & - & - & $9.050,00$ \\
\hline 33 & Média & Granulares & Plano & Pista dupla sem revestimento & 720,00 & $1.530,00$ & $1.800,00$ & - & - & 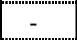 & $4.050,00$ \\
\hline 34 & Média & Granulares & Plano & Pista simples revestimento primário & 720,00 & 957,00 & $1.260,00$ & $3.125,00$ & $\begin{array}{l}- \\
-\end{array}$ & - & $6.062,00$ \\
\hline 35 & Média & Granulares & Plano & Pista simples sem revestimento & 720,00 & 957,00 & $1.260,00$ & - & - & "'?"- & $2.937,00$ \\
\hline 36 & Ruim & Granulares & Plano & Pista dupla pavimentada & 720,00 & $1.530,00$ & $1.800,00$ & & $40.160,40$ & & $44.210,40$ \\
\hline 37 & Ruim & Granulares & Plano & Pista dupla revestimento primário & 720,00 & $1.530,00$ & $1.800,00$ & $5.000,00$ & - & - & $9.050,00$ \\
\hline 38 & Ruim & Granulares & Plano & Pista dupla sem revestimento & 720,00 & $1.530,00$ & $1.800,00$ & - n & - & - n & $4.050,00$ \\
\hline 39 & Ruim & Granulares & Plano & Pista simples revestimento primário & 720,00 & 957,00 & $1.260,00$ & $3.125,00$ & - & - & $6.062,00$ \\
\hline 40 & Ruim & Granulares & Plano & Pista simples sem revestimento & 720,00 & 957,00 & $1.260,00$ & - & - & - & $2.937,00$ \\
\hline 41 & Excelente & Finos & Ondulado & Pista dupla pavimentada & 720,00 & $2.295,00$ & $1.800,00$ & & $40.160,40$ & & $44.975,40$ \\
\hline 42 & Excelente & Finos & Ondulado & Pista dupla revestimento primário & 720,00 & $2.295,00$ & $3.600,00$ & $5.000,00$ & - & - & $11.615,00$ \\
\hline 43 & Excelente & Finos & Ondulado & Pista dupla sem revestimento & 720,00 & $2.295,00$ & $3.600,00$ & - & - & - & $6.615,00$ \\
\hline 44 & Excelente & Finos & Ondulado & Pista simples revestimento primário & 720,00 & $1.435,00$ & $2.520,00$ & $3.125,00$ & - & "- & $7.800,00$ \\
\hline 45 & Excelente & Finos & Ondulado & Pista simples sem revestimento & 720,00 & $1.435,00$ & $2.520,00$ & 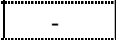 & - & 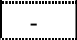 & $4.675,00$ \\
\hline
\end{tabular}

Continua...

Continued... 
Quadro 4, Cont.

Table 4, Cont.

\begin{tabular}{|c|c|c|c|c|c|c|c|c|c|c|c|}
\hline \multicolumn{5}{|c|}{ Parâmetro de Qualidade } & \multicolumn{6}{|c|}{ Atividade da Construção } & \multirow{3}{*}{$\begin{array}{c}\text { Custo } \\
\text { Total } \\
(\mathrm{R} \$ / \mathrm{km})\end{array}$} \\
\hline \multirow[b]{2}{*}{ Tipo } & \multirow[b]{2}{*}{ GH } & \multirow{2}{*}{$\begin{array}{c}\text { Solo } \\
\text { Subleito }\end{array}$} & \multirow[b]{2}{*}{ Greide } & \multirow[b]{2}{*}{ Largura/Tipo Pavimento } & \multirow{2}{*}{\begin{tabular}{|c|} 
Lev. \\
topog. \\
$(\mathrm{R} \$ / \mathrm{km})$
\end{tabular}} & \multirow{2}{*}{\begin{tabular}{|c|} 
Limp+ \\
terrap. \\
$(\mathrm{R} \$ / \mathrm{km})$
\end{tabular}} & \multirow{2}{*}{$\begin{array}{c}\text { Drenagem } \\
(\mathrm{R} \$ / \mathrm{km})\end{array}$} & \multicolumn{3}{|c|}{ Pavimentação (R $\$ / \mathrm{km})$} & \\
\hline & & & & & & & & $\begin{array}{c}\text { Rev. } \\
\text { Primário }\end{array}$ & $\begin{array}{c}\text { Rev. } \\
\text { Asfáltico }\end{array}$ & $\begin{array}{l}\text { Sem } \\
\text { Rev. }\end{array}$ & \\
\hline 46 & Boa & Finos & Ondulado & Pista dupla pavimentada & 720,00 & $2.295,00$ & $1.800,00$ & & $40.160,40$ & & $44.975,40$ \\
\hline 47 & Boa & Finos & Ondu & Pista dupla revestimento primário & 720,00 & $2.295,00$ & & 000,00 & 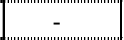 & - & $11.615,00$ \\
\hline 48 & Boa & Finos & Ondulado & Pista dupla sem revestimento & 720,00 & $2.295,00$ & $3.600,00$ & - & " - & - & $6.615,00$ \\
\hline 49 & Boa & Finos & Ondulado & Pista simples revestimento primário & 720,00 & $1.435,00$ & $2.520,00$ & $3.125,00$ & - & - & $7.800,00$ \\
\hline 50 & Boa & Finos & Ondulado & Pista simples sem revestimento & 720,00 & $1.435,00$ & $2.520,00$ & (3) & (3)"- & - & $4.675,00$ \\
\hline 51 & Média & Finos & ndulado & Pista du & 720,00 & $2.295,00$ & $1.800,00$ & & $40.160,40$ & & $44.975,40$ \\
\hline 52 & Média & Finos & Ondulado & Pista di & 720,00 & $2.295,00$ & $3.600,00$ & $5.000,00$ & - & - & $11.615,00$ \\
\hline 53 & Média & Finos & Ondulado & Pista dupla sem revestimento & 720,00 & $2.295,00$ & $3.600,00$ & - & - & - & $6.615,00$ \\
\hline 54 & Média & Finos & Ondu & Pista simples revestimento primár & 720,00 & $1.435,00$ & 520,00 & $3.125,00$ & - & - & $7.800,00$ \\
\hline 55 & Média & Finos & & (1) & 720,00 & $1.435,00$ & 20,00 & - & - & - & $4.675,00$ \\
\hline 56 & Ruim & Finos & Ondulado & Pista dupla pavimentada & 720,00 & $2.295,00$ & $1.800,00$ & & $40.160,40$ & & $44.975,40$ \\
\hline 57 & Ruim & Finos & Ondulado & Pista dupla revestimento primário & 720,00 & $2.295,00$ & $3.600,00$ & 000,00 & - & - & $11.615,00$ \\
\hline 58 & Ruim & Finos & 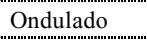 & 1 & 720,00 & $2.295,00$ & 0,00 & - & - & - & 5,00 \\
\hline 59 & Ruim & Finos & lado & w & 720,00 & $1.435,00$ & 0,00 & $3.125,00$ & - n & - &, 00 \\
\hline 60 & Ruim & Finos & ndulado & Pista si & 720,00 & $1.435,00$ & 20,00 & - & - & - & 5,00 \\
\hline 61 & Excelente & Granula & O & $\mathrm{Pi}$ & 720,00 & $2.295,00$ & & & $40.160,40$ & & $44.975,40$ \\
\hline 62 & Excelente & Granulares & & & 720,00 & $2.295,00$ & & $5.000,00$ & " ne"- & - & 11. \\
\hline 63 & Excelente & Granulares & Onc & Pista d & 720,00 & $2.295,00$ & 00,00 & - & "'-"'- & - & $6.615,00$ \\
\hline 64 & Excelente & Granulares & Ondul & Pistas & 720,00 & $1.435,00$ & 20,00 & $.125,00$ & - & - & $7.800,00$ \\
\hline 65 & Excelente & Granulares & Ondulado & Pista simples sem revestimento & 720,00 & $1.435,00$ & 520,00 & -"'- & "'-"'-' & - & 5,00 \\
\hline 66 & Boa & Granulares & Ondulado & Pista d & 720,00 & $2.295,00$ & 0,00 & & .160 & & 44. \\
\hline 67 & Boa & Granulares & Ondulado & Pista dupla reve & 720,00 & $2.295,00$ & $3.600,00$ & $5.000,00$ & - & - & $11.615,00$ \\
\hline 68 & Boa & Granulares & Ondulado & estimento & 720,00 & $2.295,00$ & $3.600,00$ & - & - & - & $6.615,00$ \\
\hline 69 & Boa & Granul & Ondul & Pista si & 720,00 & $1.435,00$ & 520,00 & $3.125,00$ & "'-"' & - & 0,00 \\
\hline 70 & Boa & es & lo & to & 720,00 & $1.435,00$ & 0,00 & - & - & - & 5,00 \\
\hline 71 & Média & Granulares & Ondulado & Pista dupla & 720,00 & $2.295,00$ & 0,00 & & $40.160,40$ & & 44. \\
\hline 72 & Média & Granulares & Ondulado & Pista dupla & 720,00 & $2.295,00$ & $3.600,00$ & $5.000,00$ & - & - & 5,00 \\
\hline 73 & Média & & & & 720,00 & $2.295,00$ & & - & - & - & \\
\hline 74 & Média & Granulares & Ondulado & ento primá & 720,00 & $1.435,00$ & 0,00 & $3.125,00$ & " - & - & $7.800,00$ \\
\hline 75 & Média & Granulares & Ondulado & Pista simples sem revestimento & 720,00 & $1.435,00$ & $2.520,00$ & . & - & - & $4.675,00$ \\
\hline 76 & Ruim & Granulares & Ondulado & Pista dupla pavimentada & 720,00 & $2.295,00$ & 800,00 & & $40.160,40$ & & $44.975,40$ \\
\hline 77 & Ruim & Granulares & Ondulado & ta dupla revest & 720,00 & $2.295,00$ & $3.600,00$ & $5.000,00$ & "'m-"'- & - & $11.615,00$ \\
\hline 78 & Ruim & Granulares & Ondulado & Pista dupla sem revestimento & 720,00 & $2.295,00$ & $3.600,00$ & - - & 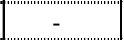 & - & $6.615,00$ \\
\hline 79 & Ruim & Granulares & Ondulado & Pista simples revestimento primário & 720,00 & $1.435,00$ & $2.520,00$ & $.125,00$ & - & - & $7.800,00$ \\
\hline 80 & Ruim & Granulares & Ondulado & Pista simples sem revestimento & 720,00 & $1.435,00$ & $2.520,00$ & - & - n & - & 5,00 \\
\hline 81 & Excelente & Finos & Montanhoso & Pista dupla pavimentada & 720,00 & $3.060,00$ & $1.800,00$ & & 160 & & $45.740,40$ \\
\hline 82 & Excelente & Finos & Montanhoso & Pista dupla revestimento primário & 720,00 & $3.060,00$ & $5.400,00$ & $5.000,00$ & - & - & $14.180,00$ \\
\hline 83 & Excelente & Finos & Montanhoso & Pista dup & 720,00 & $3.060,00$ & 400,00 & - & - & - & $9.180,00$ \\
\hline 84 & Excelente & Finos & Montanhoso & Pista simples revestimento primá & 720,00 & $1.913,00$ & $3.780,00$ & $3.125,00$ & " - - & - & $9.538,00$ \\
\hline 85 & Excelente & Finos & Montanhoso & Pista simples sem revestimento & 720,00 & $1.913,00$ & $3.780,00$ & - & - & - & $6.413,00$ \\
\hline 86 & Boa & Finos & Montanhoso & Pista dupla pavimentada & 720,00 & $3.060,00$ & $1.800,00$ & & $40.160,40$ & & $45.740,40$ \\
\hline 87 & Boa & Finos & Montanhoso & Pista dupla revestimento primário & 720,00 & $3.060,00$ & $5.400,00$ & $5.000,00$ & - & - & $14.180,00$ \\
\hline 88 & Boa & Finos & Montanhoso & Pista dupla sem revestimento & 720,00 & $3.060,00$ & $5.400,00$ & - & - & - & $9.180,00$ \\
\hline 89 & Boa & Finos & Montanhoso & Pista simples revestimento primário & 720,00 & $1.913,00$ & $3.780,00$ & $3.125,00$ & (3)"- & - & $9.538,00$ \\
\hline 90 & Boa & Finos & Montanhoso & Pista simples sem revestimento & 720,00 & $1.913,00$ & $3.780,00$ & - & 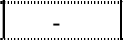 & - & $6.413,00$ \\
\hline
\end{tabular}

Continua...

Continued... 
Quadro 4, Cont.

Table 4, Cont.

\begin{tabular}{|c|c|c|c|c|c|c|c|c|c|c|c|}
\hline \multicolumn{5}{|c|}{ Parâmetro de Qualidade } & \multicolumn{6}{|c|}{ Atividade da Construção } & \multirow{3}{*}{$\begin{array}{c}\text { Custo } \\
\text { Total } \\
(\mathrm{R} \$ / \mathrm{km})\end{array}$} \\
\hline \multirow[b]{2}{*}{ Tipo } & \multirow[b]{2}{*}{$\mathrm{GH}$} & \multirow[b]{2}{*}{$\begin{array}{c}\text { Solo } \\
\text { Subleito }\end{array}$} & \multirow[b]{2}{*}{ Greide } & \multirow[b]{2}{*}{ Largura/Tipo Pavimento } & \multirow{2}{*}{$\begin{array}{c}\text { Lev. } \\
\text { topog. } \\
(\mathrm{R} \$ / \mathrm{km})\end{array}$} & \multirow{2}{*}{$\begin{array}{c}\text { Limp+ } \\
\text { terrap. } \\
(\mathrm{R} \$ / \mathrm{km})\end{array}$} & \multirow[b]{2}{*}{\begin{tabular}{|c} 
Drenagem \\
$(\mathrm{R} \$ / \mathrm{km})$
\end{tabular}} & \multicolumn{3}{|c|}{ Pavimentação (R\$/km) } & \\
\hline & & & & & & & & $\begin{array}{c}\text { Rev. } \\
\text { Primário }\end{array}$ & $\begin{array}{c}\text { Rev. } \\
\text { Asfáltico }\end{array}$ & $\begin{array}{l}\text { Sem } \\
\text { Rev. }\end{array}$ & \\
\hline 91 & Média & Finos & Iontanhoso & Pista dupla pavimentada & 720,00 & $3.060,00$ & $1.800,00$ & & $40.160,40$ & & $45.740,40$ \\
\hline 92 & Média & Finos & Yontanhoso & Pista dupla revestimento primário & 720,00 & 3.060,00 & $5.400,00$ & $5.000,00$ & - & - & $14.180,00$ \\
\hline 93 & Média & Finos & Montanhoso & Pista dupla sem revestimento & 720,00 & $3.060,00$ & $5.400,00$ & - & - & - & $9.180,00$ \\
\hline 94 & Média & Finos & Montanhoso & Pista simples revestimento primário & 720,00 & $1.913,00$ & $3.780,00$ & $3.125,00$ & - & - & $9.538,00$ \\
\hline 95 & Média & Finos & Montanhoso & Pista simples sem revestimento & 720,00 & $1.913,00$ & $3.780,00$ & - & - & - & $6.413,00$ \\
\hline 96 & Ruim & Finos & Montanhoso & Pista dupla pavimentada & 720,00 & $3.060,00$ & $1.800,00$ & & $40.160,40$ & & $45.740,40$ \\
\hline 97 & Ruim & Finos & Montanhoso & Pista dupla revestimento primário & 720,00 & $3.060,00$ & $5.400,00$ & $5.000,00$ & - & - & $14.180,00$ \\
\hline 98 & Ruim & Finos & Montanhoso & Pista dupla sem revestimento & 720,00 & 3.060,00 & $5.400,00$ & - & - & - & $9.180,00$ \\
\hline 99 & Ruim & Finos & Montanhoso & Pista simples revestimento primário & 720,00 & $1.913,00$ & $3.780,00$ & $3.125,00$ & - & - & $9.538,00$ \\
\hline 100 & Ruim & Finos & Montanhoso & Pista simples sem revestimento & 720,00 & $1.913,00$ & $3.780,00$ & - & - & - & $6.413,00$ \\
\hline 101 & Excelente & Granulares & Montanhoso & Pista dupla pavimentada & 720,00 & $3.060,00$ & $1.800,00$ & & $40.160,40$ & - & $45.740,40$ \\
\hline 102 & Excelente & Granulares & Montanhoso & Pista dupla revestimento primário & 720,00 & $3.060,00$ & $5.400,00$ & $5.000,00$ & - & - & $14.180,00$ \\
\hline 103 & Excelente & Granulares & Montanhoso & Pista dupla sem revestimento & $\begin{array}{l}720,00 \\
7.0,00\end{array}$ & $3.060,00$ & 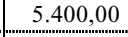 & - & - & - & $9.180,00$ \\
\hline 104 & Excelente & Granulares & Montanhoso & Pista simples revestimento primário & 720,00 & $1.913,00$ & $\begin{array}{l}3.780,00 \\
.3 .780\end{array}$ & 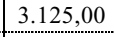 & - & - & $9.538,00$ \\
\hline 105 & Excelente & Granulares & Montanhoso & Pista simples sem revestimento & 720,00 & $1.913,00$ & $3.780,00$ & - & - & - & $6.413,00$ \\
\hline 106 & Boa & Granulares & Montanhoso & Pista dupla pavimentada & 720,00 & $3.060,00$ & $1.800,00$ & & $40.160,40$ & & $45.740,40$ \\
\hline 107 & Boa & Granulares & Montanhoso & Pista dupla revestimento primário & 720,00 & $3.060,00$ & $5.400,00$ & $5.000,00$ & - & - & $14.180,00$ \\
\hline 108 & Boa & Granulares & Montanhoso & Pista dupla sem revestimento & 720,00 & $3.060,00$ & $5.400,00$ & - & - & - & $9.180,00$ \\
\hline 109 & Boa & Granulares & Montanhoso & Pista simples revestimento primário & 720,00 & $1.913,00$ & $3.780,00$ & $3.125,00$ & - & - & $9.538,00$ \\
\hline 110 & Boa & Granulares & Montanhoso & Pista simples sem revestimento & 720,00 & $1.913,00$ & $3.780,00$ & - & - & - & $6.413,00$ \\
\hline 111 & Média & Granulares & Montanhoso & Pista dupla pavimentada & 720,00 & $3.060,00$ & $1.800,00$ & & $40.160,40$ & & $45.740,40$ \\
\hline 112 & Média & Granulares & Montanhoso & Pista dupla revestimento primário & 720,00 & $3.060,00$ & $5.400,00$ & $5.000,00$ & - & - & $14.180,00$ \\
\hline 113 & Média & Granulares & Montanhoso & Pista dupla sem revestimento & 720,00 & $3.060,00$ & $5.400,00$ & - & - & - & $9.180,00$ \\
\hline 114 & Média & Granulares & Montanhoso & Pista simples revestimento primário & 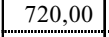 & $1.913,00$ & 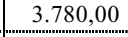 & $\begin{array}{l}3.125,00 \\
3.12 \ldots\end{array}$ & - & - & $\begin{array}{l}9.538,00 \\
.9 .53\end{array}$ \\
\hline 115 & Média & Granulares & Montanhoso & Pista simples sem revestimento & 720,00 & $1.913,00$ & $\begin{array}{l}3.780,00 \\
.3 .780\end{array}$ & - & - & - & $6.413,00$ \\
\hline 116 & Ruim & Granulares & Montanhoso & Pista dupla pavimentada & 720,00 & $3.060,00$ & $1.800,00$ & & $40.160,40$ & & $45.740,40$ \\
\hline 117 & Ruim & Granulares & Montanhoso & Pista dupla revestimento primário & 720,00 & $3.060,00$ & $5.400,00$ & $5.000,00$ & - & - & $14.180,00$ \\
\hline 118 & Ruim & Granulares & Montanhoso & Pista dupla sem revestimento & 720,00 & $3.060,00$ & $5.400,00$ & - & - & - & $9.180,00$ \\
\hline 119 & Ruim & Granulares & Montanhoso & Pista simples revestimento primário & 720,00 & $1.913,00$ & $3.780,00$ & $3.125,00$ & - & - & $9.538,00$ \\
\hline 120 & Ruim & Granulares & Montanhoso & Pista simples sem revestimento & 720,00 & $1.913,00$ & $3.780,00$ & - & - & - & $6.413,00$ \\
\hline
\end{tabular}

\subsection{Classificação e Custos de Construção de Estradas: Estudo de Caso}

A Figura 2 mostra uma visão geral de todas as estradas da área de estudo, distribuídas segundo a categoria: estradas principais, secundárias e terciárias.

Utilizando a classificação de estrada elaborada, procedeu-se à sua aplicação em todas as categorias de estradas na região de realização da pesquisa. Devido à semelhança das estradas dentro de cada categoria, os resultados foram generalizados por meio de um valor médio para todas as estradas.

A classificação de estradas da região da pesquisa encontra-se no Quadro 5. De acordo com os resultados, pode-se constatar que as estradas principais foram aquelas de melhor padrão de qualidade, devido, principalmente, às exigências de tráfego de veículos leves, pesados e extra-pesados. As estradas secundárias apresentaram um padrão de qualidade intermediário, onde a superfície de rolamento pôde ser considerada como parâmetro comprometedor, podendo impedir o tráfego de veículos em determinadas épocas do ano.

As estradas terciárias apresentaram um padrão de qualidade inferior, pois apresentam superfície da pista de rolamento sem qualquer tipo de revestimento e pista simples, podendo comprometer a trafegabilidade em determinadas épocas do ano, bem como o desempenho dos veículos de transporte. 


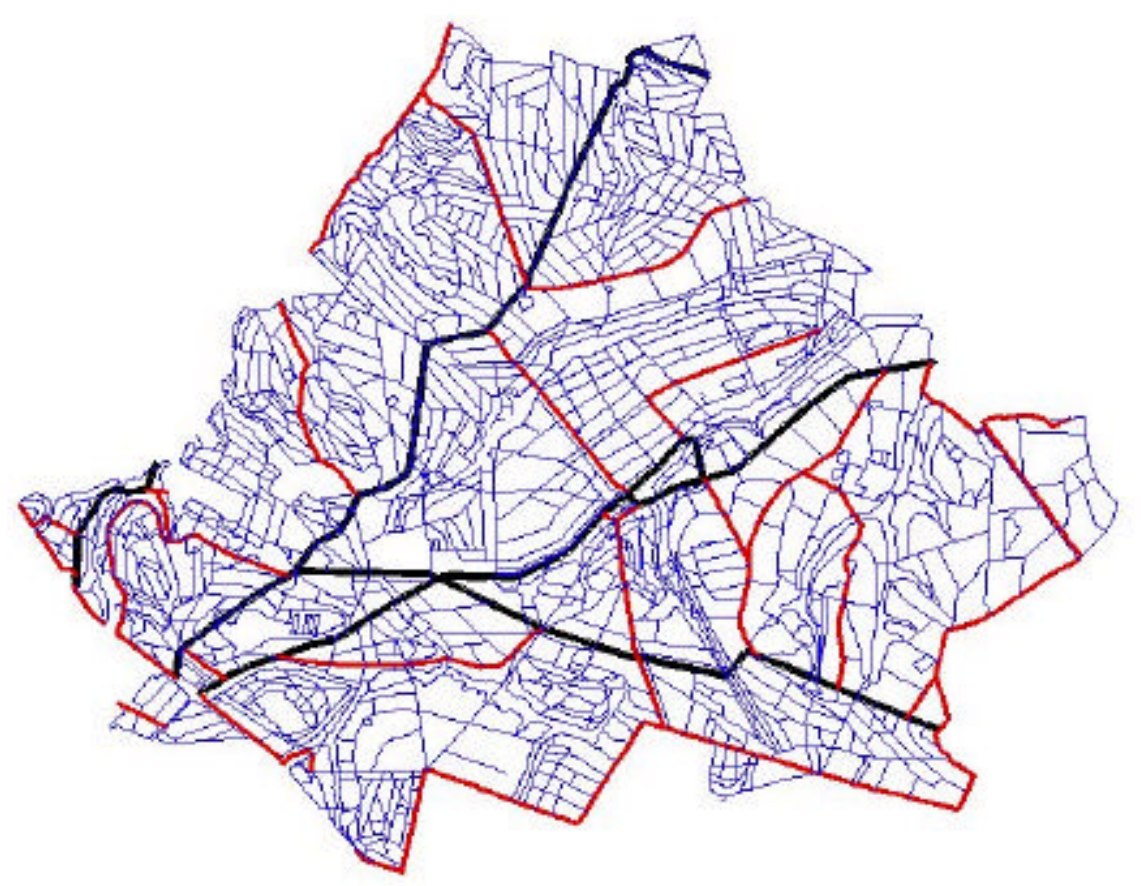

—rincipal Secundária $\longrightarrow$ Terciária

Figura 2 - Categorias de estrada florestal da área de estudo.

Figure 2 - Forest road categories in the study area.

Quadro 5 - Classificação das estradas florestais da área de estudo Table 5 - Forest road classification in the study area

\begin{tabular}{|l|l|l|l|}
\hline \multirow{2}{*}{ Fatore de Qualidade } & \multicolumn{3}{c|}{ Categoria de Estrada } \\
\cline { 2 - 4 } & \multicolumn{1}{|c|}{ Principal } & \multicolumn{1}{c|}{ Secundária } & Terciária \\
\hline Geometria horizontal & Excelente & Boa & Média \\
Superfície de rolamento & Revestimento primário & Sem revestimento & Sem revestimento \\
Solo de subleito & Granulares & Granulares & Granulares \\
Largura & Dupla & Dupla & Simples \\
Greide & Plano & Plano & Plano \\
\hline
\end{tabular}

O Quadro 6 apresenta os resultados da estimativa dos custos de construção para as categorias de estradas florestais de ocorrência na área de estudo.

Como pode ser observado, o custo de construção para as estradas principais foi mais elevado, pelo fato de elas receberem revestimento primário em toda a sua extensão, garantindo o tráfego de veículos de alta tonelagem. As estradas secundárias apresentaram um custo
Quadro 6 - Custos de construção das estradas da área de estudo

Table 6 - Forest road construction costs in the study area

\begin{tabular}{|c|c|}
\hline Categoria de Estrada & Custo de Construção $(\mathrm{R} \$ / \mathrm{km})$ \\
\hline Principal & $9.050,00$ \\
Secundária & $4.050,00$ \\
Terciária & $2.937,00$ \\
\hline
\end{tabular}


Quadro 7 - Classes de estradas florestais e desempenho dos veículos de transporte na área de estudo Table 7 - Forest road classes and transport vehicle perfomance in the study area

\begin{tabular}{|l|l|c|c|}
\hline \multirow{2}{*}{ Categoria } & \multicolumn{3}{|c|}{ Classificação das Estradas } \\
\cline { 2 - 4 } & \multicolumn{1}{|c|}{ Parâmetro de Qualidade } & Classe & Velocidade $(\mathrm{km} / \mathrm{h})$ \\
\hline Principal & GH excelente, pista dupla e revestimento primário & 5 & 41,0 \\
Secundária & GH boa, pista dupla e sem revestimento & 14 & 30,3 \\
Terciária & GH média, pista simples e sem revestimento & 19 & 24,3 \\
\hline
\end{tabular}

intermediário, uma vez que elas recebem revestimento em pontos específicos somente quando houver necessidade. As estradas terciárias apresentaram menor custo devido ao seu baixo padrão de construção e nível de tráfego, requerendo apenas reparos em pontos críticos quando do período chuvoso.

Quanto ao desempenho dos veículos de transporte nas três categorias de estradas encontradas, constata-se através do Quadro 7, que a velocidade média do veículo decresceu com o padrão de qualidade das estradas, o que pode contribuir para o aumento dos custos de transporte.

\section{CONCLUSÕES}

- A elaboração de um sistema de classificação de estradas florestais é importante para o planejamento do transporte, pois possibilita prever o desempenho dos veículos de transporte e os custos de construção, conservação e avaliação das estradas existentes.

- Na área de realização do estudo, as estradas principais apresentaram custo de construção mais elevado, fato este devido ao seu melhor padrão de qualidade, exigido pelo elevado volume de tráfego de veículos leves, pesados e extra-pesados durante todo o ano.

- De acordo com a classificação elaborada, as estradas principais, secundárias e terciárias da área estudo permitem uma velocidade média do veículo de transporte de $41,030,3$ e $24,3 \mathrm{~km} / \mathrm{hora}$, respectivamente.

- Os custos de construção de uma estrada de melhor padrão (GH excelente, topografia plana, pista dupla e revestimento asfáltico) foram de $\mathrm{R} \$ 44.210,00 / \mathrm{km}$, enquanto para uma estrada de pior qualidade (GH ruim, topografia montanhosa, pista simples e sem revestimento) foram de $\mathrm{R} \$ 6.413,00 / \mathrm{km}$.

\section{REFERÊNCIAS BIBLIOGRÁFICAS}

COMASTRI, J. A.; CARVALHO, C. A. Estradas (Traçado Geométrico). Viçosa, MG: Universidade Federal de Viçosa, 1981. 71 p. (Apostila, 112).

FERNANDES, D. C. Viabilidade do uso de alcatrão de madeira de eucalipto na estabilização de solos residuais para fins rodoviários. Viçosa, MG: Universidade Federal de Viçosa, 2000. 124p. (Doutorado em Ciência Florestal) Universidade Federal de Viçosa, 2000.

MACHADO, C. C. Sistema brasileiro de classificação de estradas florestais (SIBRACEF): Desenvolvimento e relação com o meio de transporte florestal rodoviário. Curitiba: Universidade Federal do Paraná, 1989. 188p. (Doutorado em Ciência Florestal) - Universidade Federal do Paraná, 1989.

MACHADO, C. C.; LOPES, E. S.; BIRRO, M. H. Elementos Básicos do Transporte Florestal Rodoviário. Viçosa, MG. Editora UFV, 2000. 167 p.

MACHADO, C. C.; MALINOVSKI, J. R. Rede viária florestal. Curitiba: Universidade Federal do Paraná, 1986. $157 \mathrm{p}$.

MACHADO, C. C. TransRoad. Viçosa, MG: 1991. (Software).

SENÇO, W. Manual de técnicas de pavimentação. São Paulo: Pini, 1997. 174 p.

SESSIONS, J.; SESSIONS, J. B. Scheduling and network analysis program: user's guide. Seattle: University of Washington, 1992. $610 \mathrm{p}$. 